\title{
LOS ÚLTIMOS DÍAS DE THOMAS DE QUINCEY DE RAFAEL BALLESTEROS*
}

\author{
FRANCISCO MORALES LOMAS \\ Universidad de Málaga
}

Novelar vidas de escritores posee la magia de la versatilidad, la adaptabilidad al medio, la seducción, pero también confina en su seno una perversión: el crear una sola imagen, el encerrar una perspectiva abierta, la de la vida de un escritor, $y$, en definitiva, el cercenar la amplitud de una existencia. Es un fenómeno complejo y difícil por cuanto cualquier cosa que hagamos siempre puede ser fácilmente reducida a la arbitrariedad crítica. Un riesgo que asume el novelista ab initio y su capacidad para llevar a cabo semejante contingencia debe ser también ensalzada.

\footnotetext{
* Recibido: 12-03-2009 Aceptado: 04-05-2009
} 
Lo que se propone Rafael Ballesteros en Los últimos días de Thomas de Quincey (DVD Ediciones, Barcelona, 2006) es novelar una vida, la del escritor inglés nacido en Manchester el 15 de agosto de 1785 y muy apreciado en su momento por Charles Baudelaire, Edgar Allan Poe, y, en general, por los decadentistas del XIX, sobre todo en su descripción de los mecanismos de la mente en las pesadillas:

La novela bebe de aquellos momentos históricos tan relevantes con los que, al nacer en 1785, coincidió su paso por la vida. Vivió de cerca las consecuencias de la Revolución Francesa, vive de lleno todo el hervidero del Romanticismo y participa del utilitarismo inglés que desembocó en la revolución industrial. ${ }^{1}$

Opiómano, consumidor habitual de la adormidera (de uso legal en Europa hasta 1813), Thomas de Quincey escribió tratados teóricos sobre narrativa, filosofía y economía, siendo muchos de sus textos publicados por entregas en las revistas de la época. En este sentido podemos citar su obra El asesinato considerado como una de las bellas artes (1927), resultado de su trabajo como director de la Westmorland Gazette.

Como estudiante de griego en la Universidad de Oxford, De Quincey tiene su primer contacto con la droga en 1804, pero también conoce por entonces a los poetas Coleridge (opiómano como él), y Wordsworth, su gran maestro. Se casa en 1816 con Margaret Simpson. A partir de entonces, Thomas de Quincey se verá obligado a escribir para mantener a su familia, y se sentirá agobiado a este respecto hasta que murió en Edimburgo en 1859, oprimido por la pobreza.

Las páginas más enternecedoras de su vida se refieren al encuentro con una joven enferma y aprensiva. Sin embargo su amor platónico será Ann, una muchacha de la calle, que se convertiría con el tiempo en una de las visiones más frecuentes en sus delirios de opiómano.

La producción ensayística de Quincey es de gran valor y destacamos, aparte de la citada, los estudios sobre filósofos alemanes como Kant, Lessing, Richter...,

\footnotetext{
1 C. G. Montilla, «Rafael Ballesteros dedica una novela a Thomas de Quincey», El Mundo, 20 de noviembre (2006), p. 10.
} 
además de un número singular e importante de colaboraciones en revistas y periódicos. Entre sus obras podemos nombrar A las puertas de Macbeth, Suspira de Profundis (1845), (continuación de las Confesiones), Juana de Arco (1847), El coche correo inglés (1849) y Apuntes autobiográficos (1853).

Ante esta biografía resumida, ¿cómo plantea su novela Ballesteros? Una de las grandes advertencias para cualquier narrador es cómo debe organizar su novela, qué punto de vista introducir, qué narrador debe desarrollar la trama, qué estructura u orden/desorden debe llevar, cómo ha de ser su lenguaje, su estilo... En definitiva, la arquitectura narrativa. Por cuanto, la construcción de una novela es como la de un edificio, con sus habitaciones, salones, cuartos de baño, sumideros y puntos de luz y sombras.

Ballesteros ha confesado que inicialmente quiso que su protagonista se hiciera pasar por un alumno de Kant, al que visita con frecuencia y con el que habla de política y filosofía. Y a través de esos encuentros iría relatando la degradación y muerte de Kant, de forma imaginaria; sin embargo, no lograba «encontrar el tono» a su novela desde esa perspectiva, por lo que optó por una estructura narrativa diferente:

Para Rafael Ballesteros, como en su día para Borges o Baudelaire, De Quincey evoca en cambio todo un convulso mundo, cuyos altibajos conocemos bien gracias al carácter autobiográfico de sus Confesiones de un inglés comedor de opio. En ellas se halla, sin duda, el origen de esta caleidoscópica novela, cuyo título y planteamiento son, a su vez, un guiño al ensayo inglés Los últimos días de Emmanuel Kant. ${ }^{2}$

A través de la visión de sus seres más queridos, el lector va adentrándose en la personalidad del hombre y del escritor Thomas de Quincey:

Ballesteros ofrece un recorrido cronológico no tanto por la azacaneada vida de De Quincey como por la forja de su carácter. Lo que le interesa no es tanto la trama

${ }^{2}$ R. Ruiz Garzón, «Los últimos días de Thomas de Quincey», Qué leer, febrero (2007), p. 95. 
biográfica como la perspectiva de quienes tuvieron un papel preponderante en la formación de su personalidad. ${ }^{3}$

La estructura permite hablar de novela diferida en cuanto no es ya él - que también tendrá su papel preponderante en el último apartado, el narrador - sino que serán los otros, sus familiares, los que facilitarán su visión particular, o mejor dicho, sus visiones particulares:

No me interesaba una visión directa del personaje, sino que me gustaba más relatar lo que pensaban otras personas que estuvieron cerca de él y se me ocurrió que fueran ellos los que contaran sus experiencias, para que se desvelaran sus roces con la vida, desde cinco puntos de vista fundamentales: el padre, la madre, la amante, su mujer y él mismo. ${ }^{4}$

La técnica del poliedro, organizado sobre el monólogo interior de los personajes que nos ayudan a conocer la realidad personal y vital de Thomas de Quincey, organiza el esquema narrativo, pero también la del contrapunto de ideas, perspectivas y situaciones determina el edificio narrativo, aunque bien es verdad que Rafael Ballesteros ha tendido a no repetirse y adentrarse en los acontecimientos más trascendentes, soslayando aquellos que ha considerado inanes:

Cada personaje ilumina a De Quincey y, al mismo tiempo, ilumina zonas de la personalidad de los demás y del propio narrador en cada situación; con lo que la eficacia del texto aumenta y las posibilidades de interpretación se abren para el lector. ${ }^{5}$

Creo que la novela ofrece un gran esfuerzo de contención porque es habitual en este tipo de obras explayarse innecesariamente, toda vez que es fácil, tanto por las autobiografías del propio escritor como por documentos de la época, adentrarse en una verborrea innecesaria:

La base de la narración son los propios textos del autor (Confesiones de un inglés comedor de opio; Los últimos días de Emmanuel Kant...) y los de sus biógrafos. Amplia documentación, pues, en la base de este libro, que no resta un ápice de creatividad y equilibrio al resultado. ${ }^{6}$

\footnotetext{
${ }^{3}$ D. Ródenas de Moya, «La perspectiva como arte», Libros, El Periódico de Catalunya, 15 de febrero (2007), p. II.

${ }^{4}$ R. Cortés, «Ballesteros novela la vida y obra de Thomas de Quincey», Sur, 10 de noviembre (2006).

${ }^{5}$ A. Garrido Moraga, «Thomas de Quincey y los puntos de vista», Sur, 26 de enero (2007), p. 76.

${ }^{6}$ R. Romojaro, «Cuando el autor cede su voz», $A B C$ de las Letras, 779 (2007), p. 15.
} 
Ballesteros sigue, en cierto modo, la singladura de la narrativa isabelina en general, muy circunspecta a la hora de ofrecer detalles y con un sentido bastante inglés del equilibrio narrativo, de lo que debe ser y lo que no debe ser desde un punto de vista escritural. Pero es obvio que no todo el proceso posee una aceleración similar. La novela va adquiriendo, a medida que avanza, una gran fuerza literaria (iría de menor a mayor): «El avance de la narración va concatenando los capítulos de manera que unos aclaran, continúan o refuerzan lo tratado en los otros».7

Si al principio podemos observar ciertos titubeos, a partir de la entrada en liza de Ann Northom, la amante de Thomas, la novela adquiere un inusitado interés y parece que el narrador se contagia de esa situación novelesca: «Es a partir de ahora cuando empezamos a conocer mejor la personalidad de De Quincey». ${ }^{8}$

Este hecho también va a ser destacado por Ruiz Garzón, que afirma en torno a ello lo siguiente: «La novela exhibe su mejor tono en las documentadas recreaciones de la amante, Ann, y la esposa, una entregada Margareth Simpson, cuya voz transmite con sosiego las dolencias y adicciones del autor». ${ }^{9}$

Sobre todo por el carácter libresco de ésta y su impronta literaria. Este hecho precedente entendemos que sucede porque existe una necesidad en los capítulos precedentes de crear la imagen familiar encarnada por el padre de Thomas y su madre, Elisabeth Penson, pero es una necesidad, no una concentración de intensidades para el escritor.

En realidad, Elisabeth de lo que menos habla es de Thomas. Ofrece más bien una visión familiar general, limitándose a hablar del señor Flearty, el tutor de Thomas, y de sí misma: su espíritu inconformista, su carácter soñador... Se trata de una persona culta, intelectualizada, que ama la poesía.

\footnotetext{
7 A. Moreno Ayora, «Los últimos días de Thomas de Quincey», El maquinista de la Generación, 13, (2007), p. 62.

8 Ibidem.

${ }^{9}$ R. Ruiz Garzón, op. cit.
} 
A través de un proceso organizativo fragmentario, en breves y raudas escenas, Ballesteros va de un tema a otro con la obsesión de que el exceso no sea una incontinencia innecesaria y sí la creación de los perfiles adecuados. Es como si estuviera un tanto inquieto por saber zanjar a tiempo la escena o la situación. Y de hecho, como si fuera partícipe de las ideas del escritor, dirá Elisabeth Penson: «Quiero acelerar la historia de estos hechos que me producen inquietud y zozobra».10

Sólo al final del capítulo hará algunas reflexiones sobre Thomas y enumerará algunas ideas o rasgos de su carácter, como cuando afirma que lo dominaba una inquietud incontenible que le producía pesadillas y vómitos cuando su padre, de pequeño, le contaba terribles historias. Pero también nos advierte de que

Era un niño retraído y solitario. También débil y esquivo. Estaba siempre con Jane y Elisabeth que jugaban con él como se juega con un juguete muy querido o con un cachorrillo de perro. Con suavidad y tiento. Cariñosamente [...] Thomas era un niño triste y feliz. Muy pronto advertí que tenía las manos más bellas del mundo: finas, elegantes y presurosas y me llenaba de orgullo su frente altiva, plean de volunta, de entereza y de aires soñadores. ${ }^{11}$

Incluso era muy temeroso de la autoridad del padre, meticuloso y lento, poco hablador, fácil en su comportamiento pero nunca llega a producir paz, tranquilidad o reposo.

La exposición del padre en el capítulo segundo aportaría también poca información sobre Thomas de Quincey. Sabemos que le cuenta historias terribles a su hijo, como la que interpola de Sofrás, con intención de transformar a su débil hijo en un ser fuerte:

El padre será el encargado de desvelarnos la visión masculina de la necesidad y obligación de tomar decisiones firmes y de tener una voluntad infatigable, su doble moral dividida entre el amor respetuoso y a veces hasta tierno y cómplice con su esposa y la secreta preferencia por el fetichismo sexual, además de su animadversión hacia el carácter soñador y enfermizo del hijo a quien educa en la superación de los miedos

\footnotetext{
${ }^{10}$ R. Ballesteros, Los últimos días de Thomas de Quincey, Barcelona, DVD, 2006, p. 30.

11 R. Ballesteros, op. cit., pp. 36-37.
} 
mediante relatos espectrales que dejarían huella en la posterior vida literaria y personal del escritor. ${ }^{12}$

Nos ayuda a comprender también las ideas del escritor a partir de las conservadoras del padre. De hecho tuvo nuestro escritor ideas conservadoras, aunque su creación fuera arriesgada y atrevida. La fragmentariedad y la interpolación se hace dueña de este capítulo con la «historia amorosa» de su padre y la señorita O'Learty, con la que vive un idilio de voyeur:

Yo no tocaba nada, sólo miraba... Y abría sus piernas. El olor a cenizas de su sexo. La savia salobre que germinaba allí. La rosa bulba que bullía [...] Y el cuerpo de la chica desaparecía detrás de la puertecilla; y entonces, sí, ahora me miraba a los ojos suplicándome algo que nunca supe descubrir. ${ }^{13}$

El tercer personaje-narrador de los acontecimientos será una mujer: su amante. Thomas conocerá a Ann Northom en la calle. Era una mujer del arroyo a la que se le fueron muriendo sus diez hermanos. Pero frente al idílico amor que él sintió por ella; Ann, en realidad, de quien estaba enamorada era del portugués Antonio Andrade; Thomas le importaba poco. Hacia el final del capítulo lo dirá con líricas y bellas palabras: «¿Qué nos unía en verdad? Mi amargura con su desamparo. Mi soledad con su ansia de vida. Mi final con su principio». ${ }^{14}$

Efectivamente, una mujer que venía de vuelta y un hombre que comenzaba a vivir. Es la visión que nos ofrece esta mujer soñadora que entrará en un internado en Londres del que Ballesteros reproduce los once artículos que lo gobernaban: «Dentro de mí se agotaba una especie de serenidad que inexplicablemente había mantenido en el alma». ${ }^{15}$

Sobre Thomas, como su padre y su madre anteriormente, apenas si ofrece unas pinceladas:

\footnotetext{
12 G. Busutil, «Los últimos días de Thomas de Quincey, Rafael Ballesteros», Banda, febrero 21 (2007).

${ }^{13}$ R. Ballesteros, op. cit., p.72.

${ }^{14}$ R. Ballesteros, op. cit., p. 115.

${ }^{15}$ R. Ballesteros, op. cit., p. 107.
} 
Me pareció un chico desvalido, abandonado a su suerte [...] Vi el fuego que llevaba en sus ojos. Era una mirada plana, profunda, asentada en unos ojos oscuros, grandes, que inmediatamente huyeron hacia otro lugar de la taberna; al último rincón de oscuridad. ${ }^{16}$

El capítulo más extenso e intenso corresponde a la mujer de Thomas, Margareth Simpson, hija de un granjero con la que tuvo ocho hijos. Podemos decir que en su recorrido existe mucho de novela sentimental en las relaciones que comienza con Thomas, su intento de suicidio, su permanente abandono cuidando de la plebe:

Llegaron a ser trece años, ¡trece años!, de aquí para allá, llegando a una casa, abandonando ésa para ocupar otra; aquí, la familia sola y allí, de inquilina con otra familia; vivimos en el campo, en pequeños suburbios, en las afueras de ciudades desconocidas [...] Y éramos nosotros solos. Quiero decir: los niños y yo. ${ }^{17}$

Thomas se ausentaba largamente en Londres y Edimburgo para abrir sus posibilidades de escritor, pero también vivían en una permanente zozobra por tener que hacer frente a las múltiples deudas y al agobio de los acreedores: «Y los acreedores... Dios, los acreedores, ¡Cómo sufría Thomas! Cómo lo humillaban, cómo lo avergonzaban; lo perseguían, le iban minando la salud». ${ }^{8}$

Finalmente el opio, al que necesitaba imperiosamente. Todo el proceso de la enfermedad y la adicción lo describe Margareth con fortaleza e interés para el lector, cuyas páginas en este momento ofrecen una gran intensidad a partir del momento en que le increpa para que lo asfixie y así poder perder la vida definitivamente:

— ¿Qué me pides, Thomas? ¿Me pides que te mate, que te asfixie?

- No, te pido que me liberes del sufrimiento más terrible Yo no puedo, no puedo resistir... es imposible resistirlo. Tienes que tener valor. ${ }^{19}$

Es, sin duda, el apartado más conseguido, el más literario, el más intenso y el más penetrante.

\footnotetext{
16 R. Ballesteros, op. cit., p. 110.

17 R. Ballesteros, op. cit., p. 156.

18 R. Ballesteros, op. cit., p. 157.

19 R. Ballesteros, op. cit., p. 170.
} 
En el último capítulo es el propio Thomas de Quincey el que toma las riendas del relato $\mathrm{y}$, con el mismo comienzo in media res del resto de la obra, comienza hablando de su amigo Truchk y, acto seguido, lleva a cabo un ataque fehaciente contra los profesores que no supieron inculcarle los valores de las culturas griegas y latinas.

Pronto observamos su espíritu lírico a medida que se va adentrando en ese aire bucólico que llega de su amor a los lagos y a los días soleados, pero también la necesidad de conservar el optimismo, a pesar de la concepción del perdedor de la que está imbuido: «Perder es la base de la vida. Perder los hijos, los amores, la alegría, el placer». ${ }^{20}$

Su encuentro con Wordsworth ocupa algunas páginas. Cuando lo conoció tendría cuarenta años y nos habla de la gran influencia que ejerció sobre él y cómo se emociona el maestro cuando le lee sus composiciones poéticas. También nos habla de Coleridge y su afición al opio, su mirar impetuoso, su misterio, su carácter avasallador. Admira Quincey la belleza del orden y la trascendencia de la filosofía que él amó.

Va formando pequeñas parcelas de la memoria, breves, concisas, raudas, y va conformando una visión. Es como si a Ballesteros le hubiera importado mucho organizar su mundo en torno a fragmentos de la memoria limitándose ex profeso y evitando los excesos tanto verbales como las reiteraciones innecesarias. Esta urbanidad en la expresión puede ofrecer la sensación de orden y perfección pero también un exceso de autoridad sobre el relato, como si todo estuviera demasiado organizado y estructurado, demasiado atado de pies y manos, y no se pudiera escapar un momento la narración de sí misma proyectándose a su albur. Sin embargo, hay todo un espíritu lírico que subyace en la historia, en su escritura, y actúa casi como corriente interna, una simbiosis entre la tragedia y la poesía que

\footnotetext{
${ }^{20}$ R. Ballesteros, op. cit., p. 191.
} 
organizan un mundo con un elevado valor simbólico con el que Ballesteros ha querido proyectar esta lírica vida al margen de cualquier convención. Al respecto decía Garrido Moraga:

No es una prosa lírica, no es una novela poética, ni por la intención, ni por el estilo, pero la sensibilidad en forma de lirismo, de humana y cálida visión de las cosas es una constante en estas páginas. ${ }^{21}$

Para concluir, Quincey nos ofrece su análisis psicológico, su visión de sí mismo y la atracción que tuvo para él el opio, su batalla para vencerlo y la constante sensación de felicidad a pesar de todos los percances que tuvo que soportar a lo largo de su existencia. Como dirá Moreno Ayora:

Lo cierto es que la dignidad y el sufrimiento son las dos notas comunes a las experiencias de todos los personajes. De Quincey, en su particular visión de sí mismo, confirma, pues, todas las aproximaciones biográficas que de él se han ido haciendo en los capítulos precedentes, y acaba dando una impresionante lección vital al resumir su existencia como una lucha «para hacer frente al fracaso, la adversidad, la desdicha y los infortunios».22

Ballesteros es un escritor que sabe imbuirse del tipo de novela que en cada momento está desarrollando, sabe controlar los tiempos, los espacios y los procesos. Y esta organización tan estructurada, si bien nos aporta una visión pedagógica, puede evitar los arranques de la incontinencia que puede poseer la literatura. Estamos en presencia de una obra sólida que bien puede ser la resultante de una visión del mundo, aunque es verdad que más que organizar y dirimir la existencia del escritor, en realidad observamos en mayor medida su entorno y los que vivieron con él, también una época de la historia de Inglaterra, una forma de vida, de ser y de estar en el mundo.

\footnotetext{
${ }^{21}$ A. Garrido Moraga, op. cit.

22 A. Moreno Ayora, op. cit.
} 